\title{
Vital Signs Supplemental Qualifiers Dataset
}

National Cancer Institute

\section{Source}

National Cancer Institute. Vital Signs Supplemental Qualifiers Dataset. NCI Thesaurus. Code C147268.

A dataset containing supplemental information, specifically non-standard variables, to parent records in the vital signs domain. 